\title{
CARACTERIZAÇÃO ANATÔMICO-FISIOLÓGICA DA COMPATIBILIDADE REPRODUTIVA DE AMEIXEIRA-JAPONESA ${ }^{1}$
}

\author{
DANIELA DE CONTI ${ }^{2}$, MIRIAN DE FARIAS RIBEIRO ${ }^{3}$, \\ MARIA DO CARMO BASSOLS RASEIRA ${ }^{4}$, JOSÉ ANTÔNIO PETERS 5 , \\ VALMOR JOÃO BIANCHI ${ }^{5}$
}

RESUMO - O objetivo do trabalho foi caracterizar fisiologicamente a compatibilidade reprodutiva de sete cultivares de ameixeira-japonesa (Prunus salicina Lindl) por meio de hibridações, análise de frutificação efetiva e do crescimento de tubos polínicos (CTP). O frui set foi determinado 40 dias após as hibridações controladas, realizadas a campo. O grau de compatibilidade foi avaliado in vivo, para determinar o CTP. A cv. América apresentou bom fruit set quando polinizada com as cvs. Rosa Mineira (26,7\%), Amarelinha (8,7\%) e Reubennel (12,7\%). Os cruzamentos 'Gulf Blaze' x 'Gulf Rubi', 'Gulf Rubi' x 'Gulf Rubi' e 'Gulf Rubi' x 'Gulf Blaze' obtiveram um fruit set de 11,36\%, 3,84\% e 9,94\%, respectivamente. Na polinização em laboratório, os tubos polínicos atingiram o óvulo ou ovário nesses cruzamentos, com exceção da autopolinização da 'Gulf Rubi'. No campo, não houve frutificação efetiva na autopolinização da 'América' e 'Gulf Blaze' e no cruzamento da 'América' x 'Pluma 7'. Os tubos polínicos nesses cruzamentos não chegaram a atingir o óvulo, com exceção da autopolinização da 'Gulf Blaze'. Concluiu-se que apenas os cruzamentos entre 'América' x 'Pluma 7' são incompatíveis, e a cultivar América é autoincompatível.

Termos para indexação: Prunus salicina, autoincompatibilidade, fruit set, hibridizações, polinização in vivo.

\section{ANATOMIC AND PHYSIOLOGICAL CHARACTERIZATION OF REPRODUCTIVE COMPATIBILITY OF JAPANESE PLUM}

\begin{abstract}
The objective of this study was to physiologically characterize the reproductive compatibility of seven Japanese plum cultivars (Prunus salicina Lindl) through hybridization, fruit set and pollen tube growth (PTG) analysis. The fruit set was determined 40 days after the controlled hybridization and was carried out under field conditions. The degree of compatibility was evaluated in vivo, to determine the PTG. The cv. América had good fruit set when pollinated with cvs. Rosa Mineira (26.7\%), Amarelinha (8.7\%) and Reubennel (12.7\%). The crosses between 'Gulf Blaze' x 'Gulf Rubi', 'Gulf Rubi x Gulf Rubi' and 'Gulf Rubi x Gulf Blaze' had fruit set of $11.36 \%, 3.84 \%$ and $9.94 \%$ respectively. In the laboratory tests PTG reached the egg or the ovary in all these crosses, with the exception of self-pollination of 'Gulf Rubi'. In the field, no fruit set in self-pollination of 'América' and 'Gulf Blaze' and the cross between 'América $x$ Pluma 7' was observed. The PTG in these crosses did not reach the egg, with the exception of self-pollination of 'Gulf Blaze'. It was concluded, that only the cross between 'América' x 'Pluma 7' is incompatible, and America is a self-incompatible cultivar.
\end{abstract}

Index terms: Prunus salicina, self-incompatibility, fruit set, hybridizations, in vivo pollination.

\footnotetext{
'(Trabalho 049-13). Recebido em: 16-01-2013. Aceito para publicação em: 06-09-2013.

${ }^{2}$ Bióloga, Doutoranda em Recursos Genéticos Vegetais, - Departamento de Fitotecnia - Universidade Federal de Santa Catarina SC, Bolsista CAPES. E-mail: danideconti@yahoo.com.br.

${ }^{3}$ Bióloga, Doutoranda em Fisiologia Vegetal, PPGFV - Departamento de Botânica - Instituto de Biologia - Universidade Federal de Pelotas - RS, Bolsista CAPES. E-mail: mirianfribeiro@yahoo.com.br.

${ }^{4}$ Engenheira Agrônoma, Dr., Pesquisadora da Embrapa Clima Temperado, Bolsista CNPq, Pelotas-RS. E-mail: maria.bassols@cpact. embrapa.br.

${ }^{5}$ Engenheiro Agrônomo, Prof. Dr. do Departamento de Botânica - Instituto de Biologia - Universidade Federal de Pelotas - RS. E-mail: japeters1@hotmail.com; valmorjb@yahoo.com.
} 


\section{INTRODUÇÃO}

A ameixeira-japonesa (Prunus salicina Lindl.) é uma frutífera de clima temperado cultivada economicamente em várias partes do mundo. No Brasil, é uma das espécies de ameixeira mais cultivada, pois apresenta condições climáticas favoráveis ao seu cultivo (BIASI, 2004).

Mesmo com grande potencial de cultivo no Brasil, alguns fatores têm limitado o aumento da produção nacional de ameixas, destacando-se a incapacidade de autopolinização de muitas cultivares (RASEIRA, 2003), havendo a necessidade do uso de plantas polinizadoras no pomar.

A maioria das cultivares de ameixajaponesa possui o sistema de autoincompatibilidade gametofítica, determinado pela presença de um loco multialélico, contendo os denominados alelos-S (TAKAYAMA; ISOGAI, 2005), que em cruzamentos incompatíveis codificam para enzimas que interrompem o crescimento do tubo polínico no processo de polinização (SAPIR et al., 2004). Sendo assim, a escolha de cultivares polinizadoras nem sempre é uma tarefa fácil, pois além de florescer na mesma época da cultivar produtora, devem possuir alelos-S diferentes para garantir a fecundação das flores e a produção de frutos.

A reação de autoincompatibilidade gametofítica é geneticamente determinada pela presença de um loco polimórfico (S), codificando dois genes ligados que determinam os fenótipos do pólen e do pistilo (KAO; TSUKAMOTO, 2004; MCCLURE et al., 2011; MATSUMOTO et al., 2012). Quando o alelo-S do grão de pólen é diferente dos dois alelos-S do pistilo, o tubo polínico cresce através do pistilo e fertiliza o óvulo. Quando o alelo-S expresso no pólen é o mesmo que qualquer um dos dois alelos-S expressos no pistilo, o crescimento do tubo polínico é interrompido, não ocorrendo a fecundação. O fruit set, como resultado da polinização bem-sucedida, é um dos requisitos para se obter alto rendimento na produção de ameixa-japonesa (GUERRA et al., 2009). Sendo assim, a autoincompatibilidade gametofítica entre cultivares deve ser considerada no planejamento do pomar.

Métodos confiáveis para determinar a compatibilidade entre as diferentes cultivares incluem a caracterização fisiológica através de polinizações controladas a campo, combinadas com análises laboratoriais, para determinar a viabilidade dos grãos de pólen (SOUZA; RASEIRA, 1998). Além disso, técnicas de microscopia permitem analisar características associadas à germinação dos tubos polínicos e suas taxas de crescimento, servindo também para analisar hibridações efetivas em programas de melhoramento genético e, assim, elucidar características referentes à incompatibilidade reprodutiva, sendo considerado um teste de grande valia, pois elimina resultados falsos de incompatibilidade por não serem influenciados pelos fatores ambientais, a que, a polinização realizada a campo está sujeita (COMPANY et al., 2013).

Considerando o exposto, o trabalho teve por objetivo caracterizar fisiologicamente a compatibilidade reprodutiva de cultivares de ameixeira-japonesa, por meio de avaliação do fruit set e do crescimento de tubo polínico.

\section{MATERIAL E MÉTODOS}

As análises de caracterização fisiológica da compatibilidade das cultivares de $P$. salicina Lindt foram realizadas a campo e no laboratório de melhoramento genético, na estação experimental da Embrapa Clima Temperada (Pelotas-RS) (Latitude $31^{\circ} 42^{\prime}$ e longitude $52^{\circ} 21^{\prime}$ ), durante dois anos (2010 e 2011). Foram escolhidas para o estudo as principais cultivares recomendadas e utilizadas para cultivo nas condições climáticas da região Sul do Brasil, em especial nos Estados do RS e SC, que possuem como características boa adaptação climática, produção e qualidade de fruta. Para isso foram realizadas hibridações controladas, com as seguintes combinações de cultivares: América como genitor feminino, polinizada com América, Rosa Mineira, Pluma 7 e Reubennel; Gulf Blaze como genitor feminino, sendo Gulf Blaze e Gulf Rubi os genitores masculinos; Gulf Rubi como genitor feminino, sendo Gulf Blaze e Gulf Rubi os genitores masculinos.

Nas hibridações a campo, para cada cruzamento, foram utilizadas 150 flores em estádio de balão, sendo estas emasculadas, polinizadas e ensacadas com tecido não tecido (TNT) branco, por uma semana. Após 40 dias, foi avaliada a percentagem de frutificação efetiva (fruit set) em relação ao número de flores polinizadas e ensacadas. Foram realizadas as autopolinizações das cultivares produtoras, nas quais os botões florais foram emasculados e polinizados com o pólen da própria cultivar.

$\mathrm{Na}$ polinização in vivo, foram coletados quatro ramos de cada planta, com pelo menos 20 flores em estádio de balão e acondicionados no laboratório $\left(18-20^{\circ} \mathrm{C}\right)$. As flores foram emasculadas e polinizadas manualmente com o pólen de interesse, de acordo com as combinações de cruzamentos.

Após 120 e 140 horas, os pistilos foram coletados, fixados em solução FAA 70 (1:1:8, formol, 
ácido acético e álcool etílico a 70\%) e armazenados em geladeira a $4^{\circ} \mathrm{C}$, posteriormente avaliados quanto à percentagem de grãos de pólen germinados $\mathrm{e}$ o crescimento do tubo polínico (CTP) no pistilo, por meio de coloração histoquímica, conforme o método de Wilson e Brown (1957). As lâminas com os pistilos foram analisadas em microscópio óptico Zeiss, com ocular de 10x e objetiva de 40x. Foram observadas 20 lâminas para cada combinação de cruzamento. Avaliaram-se a percentagem de grãos de pólen germinados e o grau de crescimento do tubo polínico (CTP) no pistilo, por meio da atribuição de notas de 1 a 7 (1-tubo polínico no estigma, sem penetrar no estilete; 2-tubo polínico no primeiro terço do estilete; 3- tubo polínico no segundo terço do estilete; 4- tubo polínico no terceiro terço do estilete; 5- tubo polínico no interior do ovário; 6tubo polínico próximo ao óvulo; 7- tubo polínico no óvulo), baseado na classificação de Bandeira et al. (2011). Nos cruzamentos realizados a campo, foi avaliada a percentagem de frutificação efetiva das 150 flores polinizadas, e, nos cruzamentos in vivo, utilizou-se o delineamento experimental inteiramente casualizado, com quatro repetições de cinco flores. Realizou-se a análise de variância dos dados, e as médias foram comparadas pelo teste de Tukey, a 5\% de probabilidade de erro. Os dados da variável percentagem de grãos de pólen germinados no pistilo foram transformados para $(\mathrm{x} / 100)^{1 / 2}$, e os graus de desenvolvimento do tubo polínico, transformados para $\log (\mathrm{x})$.

\section{RESULTADOS E DISCUSSÃO}

Pelos resultados de frutificação efetiva, percentagem de grãos de pólen germinados e grau de crescimento do tubo polínico obtidos nas autofecundações e hibridações, verifica-se que houve um comportamento diferenciado entre as diferentes cultivares e entre os dois diferentes anos de avaliação (Tabela 1, Figura 1).

Nos cruzamentos realizados a campo, no ano de 2011, a cv. América apresentou boa percentagem de frutificação efetiva de $26,7 \%, 8,7 \%$ e $12,7 \%$, quando polinizada com as cvs. Rosa Mineira, Amarelinha e Reubennel, respectivamente (Tabela 1). Segundo Van e Bester (1979), 5\% de frutificação efetiva em ameixeira seria suficiente para assegurar boa produção comercial. Neste mesmo ano, a cv. Gulf Blaze mostrou-se compatível quando polinizada com a cv. Gulf Rubi (11,36\%), e a cv. Gulf Rubi mostrouse compatível com a cv. Gulf Blaze $(9,94 \%)$ e com seu próprio pólen $(3,84 \%)$, (Tabela 1$)$.
Porém, no ano de 2010, a frutificação ocorreu somente quando a cv. América foi polinizada com a cv. Rosa Mineira (0,66\%), a cv. Gulf Blaze polinizada com a cv. Gulf Rubi $(9,8 \%)$ e a cv. Gulf Rubi polinizada com a cv. Gulf Blaze $(2,4 \%)$ (Tabela 1). Nos demais cruzamentos, não houve frutificação, mas mesmo assim não é possível afirmar que a falta de frutificação tenha ocorrido devido à incompatibilidade, sendo que este fato pode estar relacionado a fatores ambientais que podem influenciar no sucesso da frutificação.

Além do gradiente de incompatibilidade reprodutiva que pode existir entre as cultivares, as condições climáticas (chuva, vento, geada e seca) no momento da polinização e após o florescimento são relevantes, pois podem interferir no sucesso da polinização efetiva (WEINBERGER, 1975). Entretanto, o teste a campo é necessário, devendo ser complementado com polinização controlada em laboratório, seguida da análise da germinação e do crescimento dos tubos polínicos no pistilo, a fim de obter um diagnóstico mais confiável sobre o gradiente de incompatibilidade da cultivar e entre as cultivares (COMPANY et al., 2013).

No ano de 2010, segundo o Laboratório de Agrometeorologia da Embrapa Clima Temperado (CPACT) - Pelotas-RS, houve aumento da temperatura acima do normal no mês de setembro, causando o ressecamento dos botões florais que já haviam florescido. Somado a isso, sucedeu-se elevada precipitação no mesmo mês, prejudicando a polinização controlada a campo. Já no ano de 2011, a temperatura e a precipitação foram favoráveis, resultando numa sincronia na floração e na fecundação, ocorrendo assim boa frutificação.

Embora o crescimento incompleto da estrutura do óvulo e do saco embrionário possa, em parte, estar sob controle genético, a degeneração e o aborto do óvulo podem sofrer influência de fatores climáticos (LILLECRAPP et al., 1999), e que segundo Nava et al. (2009), podem explicar as variações nos resultados de frutificação entre pomares distintos da mesma cultivar e as diferenças ao longo dos anos. A falta de fecundação pode ser devida, entre outros fatores, a altas temperatura que antecipam a antese $\overline{\bar{y}}$ quando os óvulos ainda estão imaturos (NAVA et al., 2009) e podem, inclusive, degenerar o gametófito masculino (ALBUQUERQUE et al., 2000).

Em relação aos cruzamentos in vivo, foi observada baixa percentagem de grãos de pólen germinados no estigma, no ano de 2010 , em todas as cultivares avaliadas, sugerindo que muitos dos grãos de pólen estariam inviáveis (Tabela 1), pois a percentagem de grãos de pólen germinados no 
estigma, no ano de 2011, foi maior em relação a 2010. No ano de 2010, no parental feminino 'América', os grãos de pólen da cv. Pluma 7 apresentaram 36,7\% de germinação, diferindo das cultivares Amarelinha $(18,4 \%)$ e América $(8,0 \%)$, mas não diferindo das cultivares Reubennel $(25,8 \%)$ e Rosa Mineira $(26,1 \%)$. Nos cruzamentos realizados com a cv. Gulf Blaze, não houve diferença em nenhuma das cultivares testadas (Tabela 1). Entretanto, em 2011, a maior percentagem de grãos de pólen germinados no estigma da cv. América foi dos grãos provenientes da cv. Reubennel (57,3\%), diferindo das cvs Amarelinha $(34,8 \%)$, Rosa Mineira (41,3\%) e América (37,1\%) (Tabela 1). Quando os parentais femininos foram 'Gulf Blaze' e 'Gulf Rubi', não houve diferença na percentagem de grãos de pólen germinados em nenhuma das cultivares testadas como polinizadoras (Tabela 1).

Para o grau de desenvolvimento do tubo polínico (CTP), no ano de 2010, nos cruzamentos realizados com a cv. América como genitor feminino, o pólen das cultivares Pluma 7 e Reubennel apresentaram CTP até o estádio 2 (Figura 1A). Quando se utilizou o pólen da cv. Amarelinha, cerca de $10 \%$ dos tubos polínicos cresceram até o estádio 3 (Figura 1A). Para a cv. Rosa Mineira, verificou-se que $5 \%$ dos grãos apresentaram CTP até o estádio 6 , ou seja, tubo polínico próximo ao óvulo. $\mathrm{Na}$ autopolinização da cv. Gulf Blaze, os grãos de pólen apresentaram CTP até o estádio 2, porém com $85 \%$ de incidência no estádio 1. Já, na cv. Gulf Rubi, o CTP foi até o estádio 3 (Figura 1B).

Em 2011, pôde-se observar que, nos cruzamentos realizados com a cv. América, o pólen das cultivares Amarelinha, Reubennel e Rosa Mineira apresentaram CTP até o estádio 6 (tubo polínico próximo ao óvulo). O tubo polínico da cv. América e Pluma 7 atingiram 5 e $25 \%$ de incidência no grau 3 (tubo polínico no segundo terço do estilete), respectivamente, não apresentando crescimento nos estádios posteriores (Figura 1C). Quando se utilizou a cv. Gulf Blaze como genitor feminino, o pólen da própria cultivar apresentou CTP até o estádio 6 , e os grãos de pólen da cv. Gulf Rubi apresentaram CTP até o estádio 5 (Figura $1 \mathrm{D})$. Entretanto, quando se utilizou a cv. Gulf Rubi como genitora feminina, ambas as cultivares, Gulf Rubi e Gulf Blaze, apresentaram CTP até o estádio 3 (Figura 1E).

Embora não tenha ocorrido a frutificação efetiva durante a autopolinização realizada a campo da cv. Gulf Blaze, houve CTP até o óvulo (estádio 6), o que confirma a autocompatibilidade reprodutiva. Uma vez que, para ser considerada compatível, o tubo polínico precisa ultrapassar a barreira da incompatibilidade que se localiza no terço médio do estilete (SCHIFINO-WITTMANN; DALL'AGNOL, 2002), e isso foi evidenciado nesta cultivar, onde o crescimento do tubo polínico ocorreu após o estádio 4.

Verificou-se que os grãos de pólen de todas as cultivares utilizadas no presente estudo (Figura 1) foram capazes de germinar no estigma, mesmo que esta percentagem tenha sido relativamente baixa. Quando se realizou a avaliação da viabilidade dos grãos de pólen, no ano de 2010, pôde-se observar baixa viabilidade em todas as cultivares polinizadoras (1-10\%). Porém, em 2011, a viabilidade foi maior, entre $13-82 \%$, o que pode ter contribuído para melhores resultados na avaliação do fruit set.

As diferenças na viabilidade do pólen de um ano para outro, na mesma cultivar, podem estar relacionadas a fatores como o estresse hídrico, além do manuseio do pólen desde sua coleta até o teste de germinação, assim como as condições nutricionais da planta. Em 2010, houve um período de maior incidência de chuva, sendo que este fato pode ter sido o principal responsável pela baixa germinação do pólen naquele ano. Em relação ao CTP das cultivares estudadas, pôde-se observar que não ocorreu a penetração do tubo polínico no óvulo, obtendo apenas crescimento próximo a ele. $\mathrm{Na}$ autoincompatibilidade gametofítica (AIG), os tubos polínicos só irão crescer até o óvulo e só irá ocorrer fecundação se o alelo presente no grão de pólen não for o mesmo do presente no tecido diploide do estilete. Por outro lado, quando os alelos são compatíveis, apresentam estrutura normal, com deposição reticulada de calose na zona nuclear e de vacuolação, que protege e permite seu desenvolvimento para que ocorra a fecundação. Já, quando os alelos são incompatíveis, ocorre a formação e depósito irregular de calose, promovendo a inibição ou a paralisação do desenvolvimento do tubo polínico, que podem romper-se devido à excessiva deposição da própria calose (SCHIFINOWITTMANN; DALL'AGNOL, 2002).

$\mathrm{O}$ fato de não ter ocorrido a penetração efetiva do tubo polínico no óvulo, mas sim sua visualização bem próxima ao mesmo, pode estar relacionada ao tempo decorrido após a polinização, pois a velocidade de crescimento do tubo polínico até o ovário é variável entre as espécies. Porém, de acordo com os resultados encontrados no presente estudo, verificou-se que, após $140 \mathrm{~h}$ da polinização in vivo,os pistilos de todas as cultivares testadas estavam secos, impróprios para avaliação, o que confirma que as $120 \mathrm{~h}$ são as mais adequadas para a avaliação do crescimento do tubo polínico destas 
cultivares de ameixeira-japonesa. Além disso, a imaturidade do órgão reprodutor feminino, no momento da polinização, também pode contribuir para a inibição do crescimento do tubo polínico para não atingir o óvulo (BANDEIRA et al., 2011). Porém, esse fato não teve influência negativa nos resultados do trabalho, pois buscou-se verificar se as cultivares são ou não compatíveis através do CTP. Para tanto, observou-se somente se o tubo polínico ultrapassou a barreira da incompatibilidade, que se localiza no terço médio do estilete (estádio 4).

Diante dos resultados das hibridações a campo e da polinização in vivo efetuada em laboratório (Tabela 1 e Figura 1), pode-se observar que os cruzamentos entre as cvs. América x Pluma 7 são incompatíveis, corroborando os dados obtidos por Bandeira et al. (2011).

Segundo Raseira (2003), a campo, para a cv. América, recomendam-se as cultivares polinizadoras Reubennel e Rosa Mineira, sendo que tal resultado também foi confirmado neste trabalho. Além destas cultivares, foi possível observar que a cultivar Amarelinha também pode ser utilizada como possível polinizadora da cv. América em trabalhos de melhoramento genético.

Com base nos resultados dos cruzamentos realizados, a cultivar Gulf Blaze pode ser considerada autocompatível (resultados de laboratório) e polinizadora da 'Gulf Rubi'. Também se verificou que os cruzamentos entre 'Gulf Rubi' x 'Gulf Rubi' e 'Gulf Rubi' x 'Gulf Blaze' podem ser considerados compatíveis.

Apesar de não ter sido registrada frutificação efetiva no ano de $2010 \mathrm{da} \mathrm{cv}$. América, utilizando como polinizadoras as cvs. Amarelinha e Reubennel, a frutificação ocorreu no ano seguinte, mostrando que os fatores climáticos podem ser determinantes no processo de frutificação efetiva entre as diversas cultivares estudadas. A verificação do crescimento do tubo polínico até o grau 6, na polinização in vivo, confirma assim a compatibilidade reprodutiva entre tais cultivares.

Em relação à autocompatibilidade da cultivar Gulf Rubi, essa pode ser atribuída à presença de um alelo relacionado à compatibilidade. Em estudos moleculares realizados por Beppu et al. (2002), as cultivares Santa Rosa, Late Santa Rosa e Beauty foram consideradas autocompatíveis e constatou-se que elas possuíam, em comum, os alelos Sc e Se. Outras cultivares testadas, 'Oishiwasesumomo' e 'Tayo', apresentaram o alelo-Sc, porém mostraram-se autoincompatíveis. Já a cultivar Rio, que amplificou o alelo-Se, apresentou crescimento normal do tubo polínico e mostrou-se autocompatível, o que demonstra que o alelo-Se foi o responsável pela autocompatibilidade presumida na cultivar 'Santa Rosa'. Tao et al. (2002) também encontraram em cultivares de damasqueiro-japonês um gene para S-RNase que poderia ser utilizado como marcador molecular de autocompatibilidade, assim como o alelo-Se, que quando detectado em ameixeirajaponesa também poderá ser utilizado para esta finalidade. Estudos futuros de avaliação molecular dos alelos-S poderão confirmar se na cv. Gulf Rubi a autocompatibilidade detectada possui relação com o alelo-Se.

A partir do conhecimento dos alelos-S responsáveis pela incompatibilidade, bem como do conhecimento de um alelo-S que possa reverter a incompatibilidade, há a possibilidade, através de métodos biotecnológicos, da transferência de alelos entre cultivares semicompatíveis, mas que apresentem sincronia de floração.

Entretanto, através da caracterização fisiológica, é possível escolher com eficácia as melhores cultivares polinizadoras para a formação de pomares, uma vez que a simples coincidência de floração entre cultivares não é uma característica confiável para tal procedimento. Aliada à técnica de caracterização molecular dos alelos-S, é possível determinar com maior precisão e confiabilidade as melhores polinizadoras, contribuindo assim para estudos de melhoramento genético e também para a implantação de pomares com cultivares compatíveis reprodutivamente. 
A

Genitor feminino ameixeira japonesa cv. América

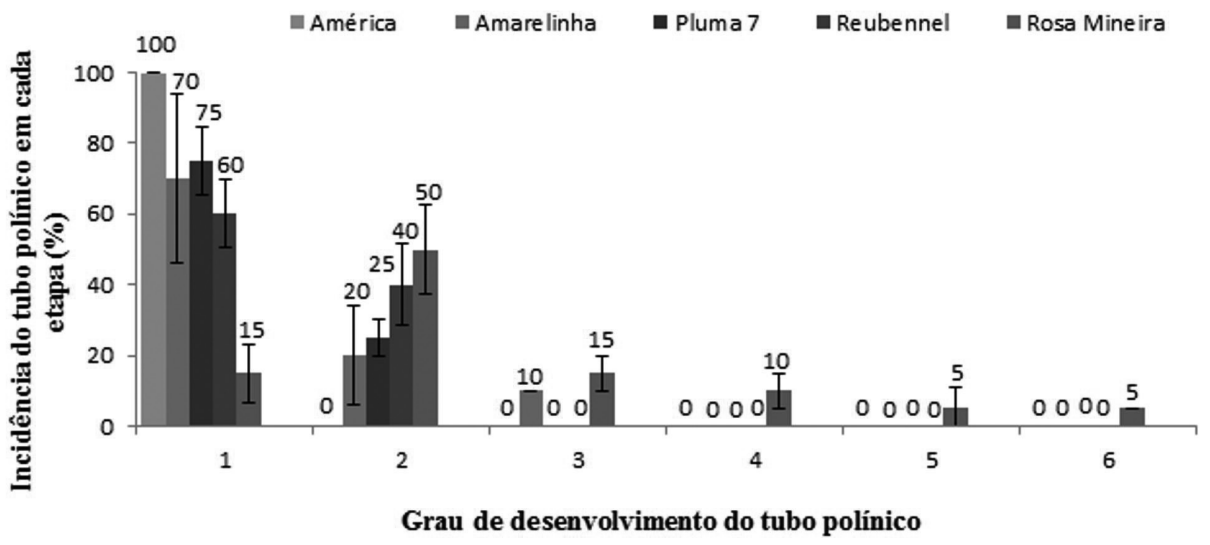

B

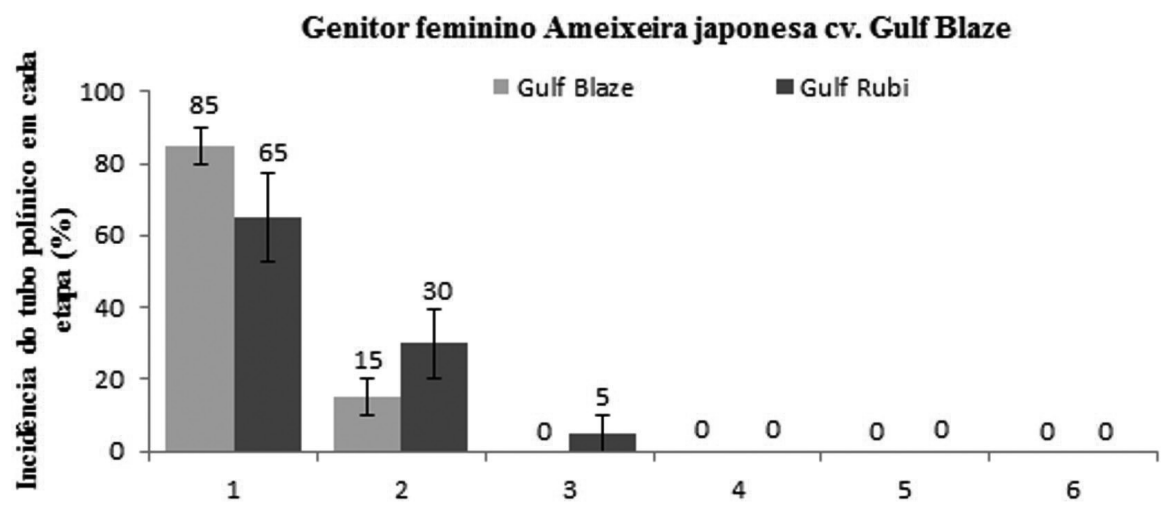

Grau de desenvolvimento do tubo polínico

\section{Genitor feminino ameixeira japonesa cv. América}

C

- América

amarelinha

- Pluma 7

neubennel

- Rosa Mineira
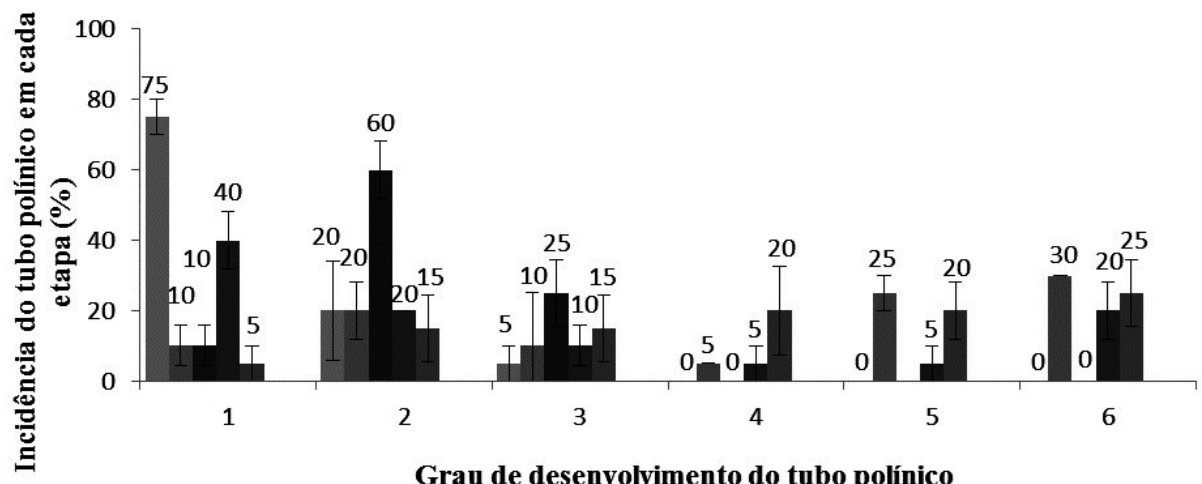

Grau de desenvolvimento do tubo polínico 
continuação..

$\mathrm{D}$

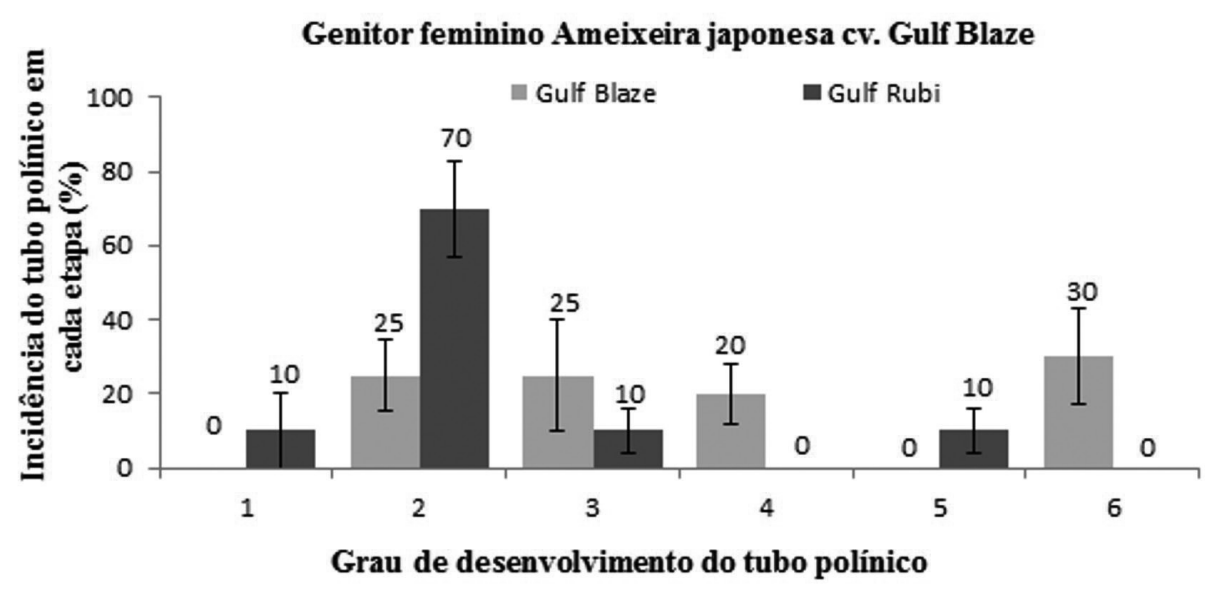

$\mathrm{E}$

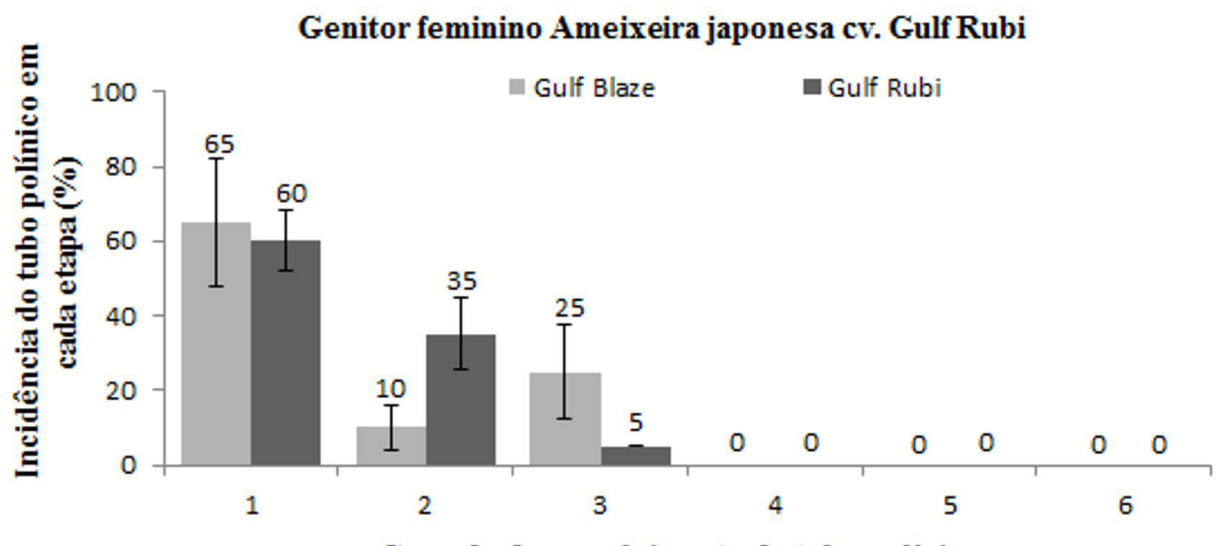

Grau de desenvolvimento do tubo polínico

FIGURA 1 - Percentagem de tubos polínicos em cada etapa do percurso estigma-óvulo de ameixeirasjaponesas (Prunus salicina), em função das polinizações controladas, realizadas in vivo, após $120 \mathrm{~h}$, e mantidas em temperatura ambiente nas genitoras femininas 'América' (A e C), 'Gulf Blaze' (B e D) e 'Gulf Rubi' (E). As barras representam o erro-padrão da média. 
TABELA 1- Percentagem de frutificação efetiva de cruzamentos realizados a campo, em ameixeiras-japonesa (Prunus salicina), nos campos da Embrapa Clima Temperada, e percentagem de grãos de pólen germinados no estigma das flores, a 120 horas da polinização in vivo ${ }^{(1)}$, na período de 2009/2010 e 2010/2011.

\begin{tabular}{|c|c|c|c|c|c|}
\hline \multicolumn{6}{|c|}{ Genitores } \\
\hline \multirow{2}{*}{ Femininos } & \multirow{2}{*}{ Masculinos } & \multicolumn{2}{|c|}{ Frutificação efetiva } & \multicolumn{2}{|c|}{ Pólen germinado no estigma } \\
\hline & & 2010 & 2011 & 2010 & 2011 \\
\hline \multirow{5}{*}{ América } & América & 0 & 0 & $8,0 \mathrm{c}$ & $37,1 \mathrm{c}$ \\
\hline & Rosa Mineira & 0,66 & 26,7 & $26,1 \mathrm{ab}$ & $41,3 \mathrm{bc}$ \\
\hline & Pluma 7 & 0 & 0 & $36,7 \mathrm{a}$ & $54,0 \mathrm{ab}$ \\
\hline & Amarelinha & 0 & 8,7 & $18,4 \mathrm{~b}$ & $34,8 \mathrm{c}$ \\
\hline & Reubennel & 0 & 12,7 & $25,8 \mathrm{ab}$ & $57,3 \mathrm{a}$ \\
\hline \multirow{2}{*}{ Gulf Blaze } & Gulf Rubi & 9,8 & 11,36 & $28,5 \mathrm{a}$ & $45,0 \mathrm{a}$ \\
\hline & Gulf Blaze & 0 & 0 & $29,5 \mathrm{a}$ & $46,3 \mathrm{a}$ \\
\hline \multirow{2}{*}{ Gulf Rubi } & Gulf Rubi & 0 & $3,84^{(2)}$ & - & $42,0 \mathrm{a}$ \\
\hline & Gulf Blaze & 2,4 & $9,94^{(2)}$ & _- & $46,7 \mathrm{a}$ \\
\hline
\end{tabular}

(1) Médias seguidas de letras iguais, em cada genitor feminino, não diferem pelo teste de Tukey, a 5\% de probabilidade.

${ }^{(2)}$ Cruzamentos realizados apenas a campo.

\section{CONCLUSÕES}

1- Avaliação do fruit set in vivo e avaliação do crescimento do tubo polínico in vitro são testes complementares entre si para se obter uma confiável caracterização da compatibilidade reprodutiva entre cultivares de ameixeira-japonesa.

2- Dos cruzamentos de ameixeira-japonesa avaliados, apenas os cruzamentos 'América' $\mathrm{x}$ 'Pluma 7' apresentam incompatibilidade reprodutiva.

3- A cultivar América é autoincompatível, enquanto as cultivares Gulf Blaze e Gulf Rubi são autocompatíveis e podem ser utilizadas em cruzamentos recíprocos.

\section{AGRADECIMENTOS}

Agradecemos ao Conselho Nacional de Desenvolvimento Científico e Tecnológico, pelo apoio financeiro.

\section{REFERÊNCIAS}

ALBUQUERQUE, N.; BURGOS, L.; EGEA, J. Consequences to fertilization of the developmental stages of apricot ovules at anthesis. Journal of Horticultural Science \& Biotechnology, Kent, v. 75 , p. 662-666, 2000.

BANDEIRA, J. M.; THUROW, L. B.; PETERS, J. A.; RASEIRA, M. C. B.; BIANCHI, V. J. Caracterização fisiológica da compatibilidade reprodutiva de ameixeira-japonesa. Pesquisa Agropecuária Brasileira, Brasília, v.46, n.8, p. 860-867, 2011.

BEPPU, K.; YAMANE, H.; YAEGAKI, H.; YAMAGUCHI, M.; KATAOKA, I.; TAO, R. Diversity of S-RNase genes and S-haplotypes in Japanese plum (Prunus salicina Lindl.). Journal of Horticultural Science \& Biotechnology, Kent, v.77, n.6, p.658-664, 2002.

BIASI, L. A.; ZANETTE, F.; PETRI, J. L.; MARODIN, G. A. B. Cultivares de fruteiras de caroço. In: MONTEIRO, L. B.; MIO, L. M. de; SERRAT, B. M.; MOTTA, A. C.; CUQUEL, F. L. Fruteiras de caroço: uma visão ecológica. Curitiba: UFPR, 2004. p.5-32. 
COMPANY, R. S.; KODAD, O.; FERNÁNDEZ, À.; ALONSO, J. M. Pollen tube growth and selfcompatibility in almond. Plants, Basel, v.2, p. 50-56, 2013.

GUERRA, M. E.; RODRIGO, J.; LOPESCORRALES, M.; WUNSCH, A. S-RNase genotyping and incompatibility group assignment by PCR and pollination experiments in Japanese plum. Plant Breeding, Berlin, v.128, n.3, p. 304-311, 2009.

KAO, T.; TSUKAMOTO, T. The molecular and genetic bases of $S$-RNase-based self-incompatibility. The Plant Cell, Rockville, v.16, n.1, p. 72-83, 2004.

LILLECRAPP, A. M.; WALLWORK, M. A.; SEDGLEY, M. Female and male sterility cause low fruit set in a clone of the 'Trevatt' variety of apricot (Prunus armeniaca). Scientia Horticulturae, Amsterdam, v.82, n. 3-4, p.255-263, 1999.

MATSUMOTO, D.; YAMANE, H.; ABE, K.; TAO, R. Identification of a Skp1-like protein interacting with SFB, the pollen S determinant of the gametophytic self-incompatibility in Prunus. Plant Physiology, Rockville, v. 159, p. 1252-1262, 2012.

MCCLURE, B.; CRUZ-GARCÍA, F.; ROMERO, C. Compatibility and incompatibility in S-RNasebased systems. Annals of Botany, Oxford, v.108, p. 647-658, 2011.

NAVA, G. A.; DALMAGO, G.A.; BERGAMASCHI, H.; PANIZ, R.; SANTOS, R. P. dos; MARODIN, G. A. B. Effect of high temperatures in the pre-blooming and blooming periods on ovule formation, pollen grains and yield of 'Granada' peach. Scientia Horticulturae, Amsterdam, v.122, n.1, p. 37-44, 2009.

RASEIRA, M.C.B. Polinização. In: CASTRO, L.A.S. Ameixa/produção. Pelotas: EMBRAPA Clima Temperado; Brasília: EMBRAPA Informação Tecnológica, 2003. p.30-33.
SAPIR G.; STERN, R. A.; EISIKOWITCH, D.; GOLDWAY, M. Cloning of four new Japanese plum S-alleles and determination of the compatibility between cultivars by PCR analysis. Journal of Horticultural Science \& Biotechnology, Kent, v. 79, n. 2, p. 223-227, 2004.

SCHIFINO-WITTMANN, M.T.; DALL'AGNOL, M. Self-Incompatibility. In Plants. Ciência Rural, Santa Maria, v.32, n.6, p.1083-1090, 2002.

SOUZA, C. M.; RASEIRA, M. C. B. Germinação in vitro de pólen de pereira. Agropecuária de Clima Temperado, Pelotas, v. 1, n. 2, p. 219-223, 1998.

TAKAYAMA, S.; ISOGAI, A. Self-Incompatibility in Plants. Annual Review of Plant Biology, Palo Alto, v.56, p.467-489, 2005.

TAO, R. HABU, T.; NAMBA, A.; YAMANE, H. Inheritance of Sf-RNase in Japanese apricot (Prunus mume) and its relation to self-compatibility. Theoretical and Applied Genetics, Heidelberg, v.105, n.2-3, p.222-228, 2002.

VAN, M. J. T.; BESTER, C. W. J. Cross-pollination requirements of the plum Cultivar Redgold. Deciduous Fruit Grower, Cape Town, v. 29, p. 152-154, 1979.

WEINBERGER, J. H. Plums. In: JANICK, J.; MOORE, J. N. (Ed.). Advances in fruit breeding. West Lafayete: Purdue University, 1975. p. 336-347.

WILSON, J. A.; BROWN, S. O. Differential staining of pollen tubes in grass pistils. Agronomy Journal, Madison, v.49, n.4, p. 220-222, 1957. 